\title{
MEKANISME INPUT SURVEILANS PNEUMONIA DI DINKES KABUPATEN LAMONGAN TAHUN 2014
}

\author{
Habibatin Nurul Fajriyah \\ Departemen Epidemiologi, Fakultas Kesehatan Masyarakat, \\ Universitas Airlangga, Surabaya, Jawa Timur, Indonesia \\ Alamat Korespondensi: \\ Habibatin Nurul Fajriyah \\ Email: hbibatin.nurul.f@gmail.com
}

\begin{abstract}
Surveillance pneumonia is a process of regular monitoring against pneumonia and increased risk of pneumonia. The purpose of this study was to determine the input system pneumonia surveillance in Health Office (DHO) Lamongan. Data were obtained from interviews with officers indept holder DHO program pneumonia in Lamongan and reinforced with indept interview to the health center. The pneumonia study conducted by descriptive method and approach that is input surveillance systems that include data sources and types of data, infrastructure, resources and sources of funding. Implementation of a surveillance system in Lamongan district health office is still not well seen from the input that data sources are from the health office health centers, inadequate infrastructure, resources do not meet the needs, and lack of financial resources. Based on the results of research advice given was increased coordination with the health centers, the use of an online system for reporting to the health office, filing budget, quality improvement officer with the holding of training.
\end{abstract}

Keywords: surveillance systems, system input, data sources and types of data, infrastructure, resources, and source of fundszzzz

\begin{abstract}
ABSTRAK
Surveilans pneumonia adalah proses pemantauan secara berkala terhadap penyakit pneumonia dan peningkatan resiko pneumonia. Tujuan penelitian ini adalah untuk mengetahui sistem input surveilans pneumonia di Dinas Kesehatan (Dinkes) Kabupaten Lamongan. Data diperoleh dari indept interview terhadap petugas pemegang program pneumonia di Dinkes Kabupaten Lamongan dan diperkuat dengan indept interview terhadap pihak Puskesmas. Penelitian pneumonia ini dilakukan dengan metode deskriptif dan menggunakan pendekatan sistem surveilans yaitu input yang meliputi sumber data dan jenis data, sarana prasarana, sumber daya dan sumber dana. Pelaksanaan sistem surveilans di Dinkes Kabupaten Lamongan masih belum baik dilihat dari input yaitu sumber data Dinkes yang dari puskesmas, sarana prasarana kurang memadai, sumber daya belum memenuhi kebutuhan, dan tidak adanya sumber dana. Berdasarkan hasil penelitian saran yang diberikan adalah peningkatan koordinasi dengan puskesmas, penggunaan sistem online dalam pelaporan ke Dinkes, pengajuan anggaran dana, peningkatan kualitas petugas dengan diadakannya pelatihan.
\end{abstract}

Kata Kunci: sistem surveilans, sistem input, sumber data dan jenis data, sarana dan prasarana, sumber daya dan sumber dana.

\section{PENDAHULUAN}

Mekanisme merupakan deretan metode, alat atau cara untuk menyelesaikan suatu masalah yang terkait dengan berjalannya suatu proses pekerjaan untuk mencapai hasil yang memuaskan (Moenir, 2001). Mekanisme untuk menyelesaikan masalah pneumonia adalah dengan surveilans pneumonia. Surveilans adalah proses pengumpulan, pengolahan, analisis dan inpretasi data 
secara teratur dan terus menerus serta penyebaran informasi kepada pihak yang berim7;siko agar segera mendapatkan tindakan penanggulangan atau antisipasi (WHO, 2004). Pada awalnya, surveilans dikenal hanya sebagai pengumpulan data dan penanggulangan KLB, untuk saat ini surveilans digunakan untuk semua masalah kesehatan.

Surveilans epidemiologi pada saat ini telah digunakan sebagai alat untuk menilai, memantau, mengawasi dan merencanakan program-program kesehatan yang akan dilaksanakan, sehingga adanya surveilans epidemiologi sangat membantu dalam perbaikan kesehatan masyarakat (Efendi, 2009). Tujuan surveilans epidemiologi adalah tersedianya data dan informasi epidemiologi sebagai dasar manajemen kesehatan untuk pengambilan keputusan dalam perencanaan, pelaksanaan, pemantauan, evaluasi program kesehatan dan peningkatan penanggulangan serta respons kejadian luar biasa yang cepat dan tepat secara menyeluruh (Bustan, 2006). Tertera pula dalam Keputusan Mentri Kesehatan Republik Indonesia nomor 1479/ MENKES/SK/X/2003, yang menjelaskan tujuan daru surveilans epidemiolohi adalah mengumpulkan semua data kesakitan yang berdasar dari pelayanan kesehatan di wilayah kerjanya, tersampaikannya penyebaran informasi hingga Dinkes, prosedur tata laksana yang dikelola dan disajikan oleh Dinkes Kabupaten/Kota setempat, penyebaran informasi hingga terbentuknya tindak lanjut sebagai umpan balik kepada puskesmas, Rumah Sakit dan Pelayanan kesehatan lainnya.

Berdasarkan Keputusan Kementrian Kesehatan RI nomor 45 tahun 2014 tentang penyelenggaraan sistem surveilans epidemiologi kesehatan, pneumonia merupakan bagian dari sasaran penyelenggaran surveilans penyakit menular sehingga butuh pelaksanaan surveilans penyakit pada penyakit tersebut.

Infeksi Saluran Pernafasan Atas merupakan penyakit saluran pernafasan yang tidak memandang usia, jenis kelamin dan tempat. Pneumonia merupakan salah satu bagian dari ISPA yang terbanyak menyerang di Negara berkembang. Pneumonia adalah infeksi yang menyerang pada jaringan penyusun paru atau disebut dengan alveoli dengan munculnya gejala batuk hingga kesukaran bernafas (sesak nafas). Salah satu penyebab pneumonia adalah bakteri Streptococcus pneumonia (SP). Penyakit pneumonia selalu masuk dalam daftar sepuluh penyakit terbanyak di setiap tahun. Hal tersebut dapat dilihat dari hasil Riskesdas 2007 yang menunjukkan bahwa pneumonia dapat mengakibatkan kematian pada balita (Kemenkes RI, 2014). Oleh sebab itu perlunya diadakannya pengendalian kasus pneumonia.

Dalam pemberantasan penyakit ISPA, program dititikberatkan pada Pengendalian dan Pemberantasan (P2) Pneumonia. Berdasarkan Keputusan Menteri Kesehatan RI nomor 1457/MENKES/SK/X/2003 tentang Standar Pelayanan Minimal di Kabupaten atau Kota, tertuang dalam BAB 2 pasal 2 disebutkan pencegahan dan pemberantasan penyakit ISPA dengan cakupan balita yang tertangani $100 \%$. Puskesmas sebagai tempat pelayanan kesehatan tingkat pertama bertanggung jawab melakukan kegiatan Pemberantasan Penyakit terutama penyakit menular. Program pemberantasan pneumonia telah dimulai sejak tahun 1984, dengan tujuan menurunkan angka kesakitan dan kematian khususnya pada bayi dan anak balita yang disebabkan oleh ISPA terlebih pneumonia.

Survei Demografi Kesehatan Indonesia pada tahun 2012 ditemukan terjadi peningkatan jika dibandingkan dengan tahun 2007, ditemukan peningkatan sebesar 9\% anak yang terlihat dengan gejala ISPA (BPS, 2013). Kejadian pneumonia banyak terjadi pada balita sebab pada anak balita status imunnya masih rendah dan gizi rendah. Prevalensi pneumonia pada balita tergambar pada hasil Survei Demografi Kesehatan Indonesia (SDKI) mengalami peningkatan dari 7,6\% pada tahun 2002 menjadi 11,2\% 
pada tahun 2007 (Kemenkes RI, 2010). Cakupan yang digunakan adalah persentase dari penemuan kasus pneumonia sampai pneumonia berat kepada target penemuan yang sudah ditetapkan pemerintah (Ditjen P2PL, 2011). Untuk mengantisipasi dan menangani kasus pneumonia pemerintah dan badan kesehatan memberikan ketentuan untuk penanggulangan. Menurut Kemenkes RI (2011), pneumonia yang menyerang pada anak diklasifikasikan sesuai dengan gejala yang dialami serta usia dari balita tersebut. Setiap klasifikasi memiliki tindakan yang berbeda dalam penanganan dan menentukan ke dalam pneumonia.

Klasifikasi pada balita yang dilakukan sesuai program P2 Pneumonia tersedia pada tabel 1. Tabel 1 menunjukkan bahwa terdapat 3 kolom warna yaitu merah, kuning dan hijau yang memiliki arti dalam menentukan derajat keparahan kasus penyakit dan penentuan terapi yang dibutuhkan. Arti tabel merah adalah pneumonia yang berat atau sangat berat segera rujuk ke Rumah Sakit, kuning adalah pneumonia bisa ditangani dengan pemerian antibiotik dan dapat dirawat di rumah, warna hijau adalah batuk bukan pneumonia sehingga bisa dilakukan perawatan di rumah saja.

Untuk mendiagnosis apakah pasien masuk dalam klasifikasi pneumonia butuh pemeriksaan yang harus dibutuhkan. World Health Organization sudah memberikan pedoman dalam pendiagnosisan kasus pneumonia berdasarkan klasifikasi yang ada. Diagnosa tersebut ditegakkan apabila pada pneumonia sangat berat terjadi sianosis atau membiru akibat kekurangan oksigen dan sulit untuk minum makan harus dirawat di rumah sakit, pada pneumonia berat terjadi retraksi namun tidak disertai sianosis dan masih bisa untuk minum maka juga harus dirawat di rumah sakit, untuk pneumonia sendiri apabila tidak adanya retraksi namun frekuensi nafas cepat dan bukan pneumonia jika hanya batuk tanpa ada tanda dan gejala seperti diagnosis yang mengarah ke pneumonia berat maka tidak diperlukan tindakan apapun (Kemenkes RI, 2012).
Tabel 1. Klasifikasi Balita Batuk dan atau Kesukaran Bernapas

\begin{tabular}{|c|c|c|}
\hline $\begin{array}{c}\text { Kelompok } \\
\text { Umur }\end{array}$ & Klasifikasi & $\begin{array}{c}\text { Tanda Penyakit } \\
\text { selain Batuk } \\
\text { dan atau Sukar } \\
\text { Bernapas }\end{array}$ \\
\hline \multirow[t]{3}{*}{2 bln $-<5$ thn } & $\begin{array}{l}\text { Pneumonia } \\
\text { Berat }\end{array}$ & $\begin{array}{l}\text { Tarikan dinding } \\
\text { dada bagian bawah } \\
\text { ke dalam (chest } \\
\text { Indrawing) }\end{array}$ \\
\hline & Pneumonia & $\begin{array}{l}\text { Napas cepat sesuai } \\
\text { golongan umur } \\
2 \text { bln }-<1 \text { thn }=50 \\
\text { kali atau lebih/menit } \\
1-<5 \text { thn }=40 \text { kali } \\
\text { atau lebih/menit }\end{array}$ \\
\hline & $\begin{array}{l}\text { Bukan } \\
\text { Pneumonia }\end{array}$ & $\begin{array}{l}\text { Tidak ada napas } \\
\text { cepat dan tidak ada } \\
\text { tarikan dinding } \\
\text { dada bagian bawah } \\
\text { ke dalam }\end{array}$ \\
\hline \multirow[t]{2}{*}{$<2$ bln } & $\begin{array}{l}\text { Pneumonia } \\
\text { Berat }\end{array}$ & $\begin{array}{l}\text { Napas cepat }>60 \text { kali } \\
\text { atau lebih/menit atau } \\
\text { tarikan kuat dinding } \\
\text { bagian bawah ke } \\
\text { dalam }\end{array}$ \\
\hline & $\begin{array}{l}\text { Bukan } \\
\text { Pneumonia }\end{array}$ & $\begin{array}{l}\text { Tidak ada napas cepat } \\
\text { dan tidak ada tarikan } \\
\text { dinding dada bagian } \\
\text { bawah }\end{array}$ \\
\hline
\end{tabular}

Sumber: Kemenkes RI, 2011

Sebagai penunjang terlaksananya dan tercapainya program yang dilaksanakan untuk pengendalian kasus pneumonia maka dibutuhkannya data yang dapat diperoleh dari kegiatan surveilans epidemiologi pneumonia. Surveilans memiliki peran penting sebagai penyedia data dan informasi kesehatan yang terjadi di suatu wilayah sehingga dapat segera diputuskan bijakan dalam melakukan penanggulangan dan pengendalian kasus.

Indonesia pernah menduduki perikat ke-6 dari seluruh dunia dalam kejadian pneumonia, tepatnya pada tahun 2006 hingga pada tahun 2008 Indonesia menduduki peringkat ke-8 (IVAC, 2011). Pada tahun 2007 yakni hasil dari Riskesdas tercatat prevalensi pneumonia balita sebesar 2,13\% dan kembali meningkat pada tahun 2013 
yaitu sebesar 4,5\% (Kemenkes RI, 2013). Dilihat dari angka cakupan pneumonia pada tahun 2007-2012 kisaran angka cakupan penemuan adalah $23-27,71 \%$ ditambah pada tahun 2012 tidak ada provinsi manapun yang bisa mencapai target dari penemuan pneumonia (Kemenkes RI, 2014).

Hasil pencatatan dan pelaporan Dinkes Provinsi Jawa Timur tahun 2012, didapatkan cakupan penderita pneumonia balita di Jawa Timur sebesar 27,08\% dengan jumlah 84.392 kasus. Target cakupan penemuan adalah $80 \%$, dari 38 kabupaten/kota yang dapat mencapai target yang ditentukan hanya 3 kabupaten, yaitu Kabupaten Bojonegoro, Kabupaten Pasuruan dan Kabupaten Gresik. Di antara Kabupaten Gresik dengan Kabupaten Bojonegoro terdapat Kabupaten Lamongan yang dalam cakupan penemuan pneumonia belum mencukupi target. Tingkat kejadian pneumonia di Kabupaten Lamongan dalam kurun waktu tiga tahun belakangan ini cenderung mengalami kenaikan dipantau dari jumlah kasus yang terlihat dari Profil Dinkes Kabupaten Lamongan. Tahun 2012 tercatat 2.304 kasus, tahun 2013 jumlah yang dialami mencapai 3.457 kasus. Pada tahun 2014 tercatat balita yang mengalami pneumonia sebanyak 4.436 kasus dari target penemuan sebanyak 8.818 kasus. Hasil tersebut didapatkan dari laporan berkala oleh 33 puskesmas.

Dari kejadian yang sudah ada hingga ketentuan dari pemerintah, tujuan dari adanya surveilans pneumonia adalah untuk mengetahui gambaran kejadian pneumonia di wilayah kerja menurut dari agen, hoat dan environment, mengetahui Case Fatality Rate (CFR) berdasarkan usia, mengkaver data epidemiologi sehingga dapat segera dideteksi, dan dapat menjalankan program ISPA yang salah satunya mencakup pneumonia.

Manejemen sistem surveilans yang memenuhi adalah terdiri input, proses dan output sehingga tercapainya tujuan surveilans yang sesuai dengan harapan. Dinkes merupakan unit pelayanan terdepan yang dekat dengan masyarakat. Pelaksana teknis dalam pelayanan kesehatan untuk deteksi kejadian pneumonia serta penyedia data kasus pneumonia sebagai bahan surveilans adalah Puskesmas selaku pelayanan kesehatan pertama yang langsung kontak dengan masyarakat.

Tujuan dilakukannya penelitian ini adalah memfokuskan pada sistem input surveilans pneumonia di Dinkes Kabupaten Lamongan tahun 2014 yang meliputi sumber dan jenis data, sarana dan prasarana, sumber daya serta sumber dana dalam pelaksanaan program surveilans pneumonia di tingkat Kabupaten/Kota maupun di tingkat sumber data yaitu Puskesmas.

\section{METODE PENELITIAN}

Penelitian ini merupakan penelitian deskriptif sehingga hanya menggambarkan keadaan yang ada di tempat atau di wilayah yang diteliti. Penelitian ini dilaksanakan di Dinkes Kabupaten Lamongan beserta wilayah kerjanya yaitu puskesmas, rumah sakit dan klinik. Penelitian dilaksanakan sejak dari bulan Oktober tahun 2015 sampai Mei 2016. Jenis dan Rancangan penelitian yang digunakan dalam penelitian ini menggunakan metode survei deskriptif yaitu penelitian yang menggambarkan suatu keadaan dalam tempat atau wilayah tertentu bisa juga objek yang diteliti berdasarkan dari hasil indept interview.

Objek penelitian dalam penelitian adalah dokumen laporan atau data yang dimiliki oleh petugas P2 Pneumonia di Dinkes Kabupaten Lamongan. Data kasus pneumonia yang didapatkan bersumber dari 33 puskesmas. Dalam penelitian ini diambil puskesmas yang paling tinggi angka kesakitan pneumonia dan paling rendah angka kesakitan pneumonia sebagai responden pembanding. Puskesmas yang paling tinggi angka kesakitan pneumonia adalah Puskesmas Paciran sebanyak 213 kasus dan yang paling rendah adalah Puskesmas Dradah sebanyak 78 kasus. Subjek penelitian dalam penelitian ini adalah petugas P2 pneumonia di Dinkes Kabupaten 
Lamongan dengan jumlah petugas 1 orang yaitu pemegang program, petugas puskesmas yang memiliki kasus pneumonia jumlah paling tinggi yang dilaporkan dan jumlah paling sedikit dalam angka kesakitan yang ditangani serta dari 11 rumah sakit diambil 1 rumah sakit sebagai pemegang program dan dari 14 klinik diambil 1 klinik yaitu kepala klinik atau pemegang Rekam medis. Indepth interview untuk data input dilakukan pada puskesmas.

Variabel penelitian ini terdiri dari input, proses, dan output. Input adalah masalah kesehatan dan sumber daya kesehatan yang ada meliputi sumber data dan jenis data, sarana penunjang yang mencakup ketenagaan, sarana dan prasarana serta anggaran dana. Proses adalah upaya kesehatan yang dilakukan untuk menangani masalah kesehatan mencakup pengumpulan data, kompolasi data, analisa data, intepretasi data dan penyebaran informasi. Output adalah hasil yang didapatkan dari pelaksanaan proses meliputi informasi epidemilogi dan umpan balik. Dalam pembahasan yang akan dibahas adalah input surveilans pneumonia di Dinkes Kabupaten Lamongan yang mencakup sumber data dan jenis data, sarana dan prasarana, sumber daya manusia dan sumber dana dalam pelaksanaan program surveilans pneumonia di wilayah kerja Dinas Kesehatan Kabupaten Lamongan. Penelitian ini sudah melalui tahap uji etik di Universitas Airlangga dengan nomor 48-KEPK.

\section{HASIL}

Lamongan merupakan salah satu Kabupaten yang berada di Jawa Timur dan berbatasan langsung dengan Laut Jawa sebelah Utara. Luas Kabupaten Lamongan adalah 1.812,80 $\mathrm{Km}^{2}$ atau $181.280 \mathrm{Ha}$. Kabupaten Lamongana memiliki 33 puskesmas dengan keterangan 32 dengan perawat dan 1 non perawat. Untuk Rumah Sakit, Kabupaten Lamongan memiliki 11 Rumah Sakit yang terdiri dari 2 Rumah Sakit Umum Daerah, 3 Rumah Sakit Khusus dan 6 Rumah Sakit Swasta.
Bagian awal dalam mengidentifikasi sumber daya yang digunakan untuk pelaksanaan kegiatan surveilans adalah input. Dalam pelaksanaan manajemen, input mencakup beberapa kegiatan yang sangat dibutuhkan bagi pelaksanaan manajemen pengumpulan data. Beberapa kegiatan yang dipantau yakni sumber data dan jenis data yang dikumpulkan, fasilitas sarana maupun prasarana, sumber daya manusia, dan sumber dana.

Hasil Indepth Interview terhadap Sumber data dan Jenis Data.

Hasil indept interview terhadap sumber data dan jenis data didapatkan, data yang diperoleh hanya didapat melalui Puskesmas setiap bulan, untuk rumah sakit dan klinik belum ada kerja sama program sehingga tidak ada pelaporan ke dinas kesehatan sehingga tidak digunakan sebagai responden dikarenakan data yang didapatkan oleh Dinkes hanya bersumber dari Puskesmas. Alasan rumah sakit dan klinik tidak memberikan jumlah kasus pneumonia ke Dinas Kesehatan karena tidak dimintanya data tersebut sehingga dari Rumah Sakit hanya memasukkan ke dalam STP bulanan Rumah Sakit sedangkan klinik tidak memiliki data kasus pneumoniasetiap bulan karena tidak adanya perintah penggolongan kasus pneumonia yang wajib dilakukan. Jenis data hanya berupa data jumlah penyakit berdasarkan umur setiap bulan. Jenis form yang dikirimkan dari Puskesmas ke Dinas Kesehatan adalah Form pneumonia.

Kendala muncul pada form yaitu perubahan form yang sedikit demi sedikit mulai berubah dari lembar lampiran format ke komputerisasi sehingga membuat petugas puskesmas kebingungan dalam pengisian terlebih pada pemegang program di puskesmas kurang mengenal kemajuan teknologi sehingga penggunaan form lama masih saja digunakan.

Petugas surveilans pneumonia di tingkat Dinas Kesehatanlah yang kesulitan sebab harus mengantri data yang 
dikumpulkan dari puskesmas ke form yang baru. Selain menghambat pekerjaan juga mengganggu program lain yang dipegang oleh pemegang surveilans pneumonia di Dinas Kesehatan Kabupaten Lamongan.

Hasil Indepth Interview terhadap Sarana dan Prasarana Penunjang

Dalam menjalankan suatu kegiatan tentu sarana dan prasarana merupakan hal yang dibutuhkan sesuai dengan pengertiannya yaitu alat atau bahan yang digunakan dalam suatu kegiatan sedangkan prasarana merupakan penunjang utama dalam pelaksanaan kegiatan. Prasarana merupakan tempat atau bangunan yang digunakan sebagai penunjang suatu kegiatan.

Keberhasilan suatu kegiatan tentu membutuhkan sarana dan prasarana yang membantu dalam pelaksanaan. Sarana dan prasarana yang tersedia di Dinkes dan puskesmas yang diamati lihat tabel 2 .

Hasil Indepth interview yang dilakukan peneliti, diperoleh hasil bahwa untuk sarana dan prasarana penunjang program surveilans pneumonia, di Dinkes memiliki 1 buku pedoman dan 1 soundtimer, sedangkan pada tingkat puskesmas tidak memiliki buku pedoman, untuk pemeriksaan hanya berpedoman pada menejemen tatalaksana yang ditempel pada sisi dinding ruangan dan hanya memiliki 1 soundtimer. Puskesmas seharusnya memiliki 3 buah pedoman kebijakan. Form yang digunakan oleh kedua puskesmas sama-sama menggunakan form pneumonia. Form dilaporkan setiap bulan kepada petugas program pneumonia di Dinkes Kabupaten. Surveilans pneumonia dari segi input di Dinkes sudah ada petugasnya dan untuk kualitas juga mampu,

Tabel 2. Sarana dan Prasarana Penunjang

\begin{tabular}{clcc}
\hline \multicolumn{1}{c}{ Tempat } & \multicolumn{1}{c}{ Sarana dan Prasarana } & Keterangan & Standart \\
\hline Dinkes & Petugas & Ada & Ada \\
& Buku Panduan & 1 & 1 \\
& Form & Ada & Ada \\
& Ruangan & Ada & Ada \\
\hline Puskesmas Dradah & Petugas & Ada & Ada \\
& Buku Panduan & - & 1 \\
& Soundtimer & 1 & 3 \\
& Stetoskop & Ada & Ada \\
& Thermometer & Ada & Ada \\
& Tabung Oksigen & Ada & Ada \\
& Form & Ada & Ada \\
& Ruangan & Ada & Ada \\
\hline Puskesmas Paciran & Petugas & Ada & Ada \\
& Buku Panduan & - & 1 \\
& Soundtimer & 1 & 3 \\
& Stetoskop & Ada & Ada \\
Thermometer & Ada & Ada \\
Tabung oksigen & Ada & Ada \\
Form & Ada & Ada \\
Ruangan & Ada & Ada \\
\hline
\end{tabular}


namun lain halnya dengan tingkat puskesmas yang dirasa masih belum memadai dari segi kuantitas dan kualitas.

Hasil Indepth Interview Sumber Daya Surveilans

Pelaksanaan program dibutuhkan tenaga yang terampil dan sesuai agar tercapainya tujuan kegiatan program. Berikut ini adalah tenaga surveilans yang melaksanakan kegiatan surveilans pneumonia lihat pada tabel 3 .

Hasil indepth interview didapatkan data petugas pengelola program pneumonia di Dinkes memiliki pendidikan terakhir Psikologi dan Puskesmas Dradah memiliki pendidikan terakhir Sekolah Perawat Kesehatan (SPK) di puskesmas Paciran memiliki pendidikan terakhir S1 Keperawatan. Petugas tersebut belum pernah mengikuti pelatihan surveilans pneumonia namun pernah mengikuti pelatihan Manajemen Terpadu Balita Sakit (MTBS) dan Menejemen Terpadu Balita Muda (MTBM) yang diadakan Dinas Kesehatan sekitar tahun 2012. Jumlah petugas pelaksana MTBS yang mendapatkan pelatihan di Dinkes terdapat 3 orang, di Puskesmas Paciran terdapat 2 yang mendapatkan pelatihan, di Puskesmas Dradah Blumbang terdapat 3 yang mendapatkan pelatihan.

Hasil Indepth interview tentang Sumber Dana

Sumber dana merupakan pemenuhan kebutuhan yang diperlukan dalam suatu pelaksanaan. Sumber dana bisa didapat dari mana saja, namun pada penelitian ini yang ditanyakan sumber dana yang berasal
Tabel 4. Sumber Dana

\begin{tabular}{lcc}
\hline \multicolumn{1}{c}{ Institusi } & Ketersediaan & Kecukupan \\
\hline Dinkes & Tidak ada & Tidak \\
Puskesmas & Tidak ada & Tidak \\
$\begin{array}{l}\text { Dradah } \\
\text { Puskesmas }\end{array}$ & Tidak ada & Tidak \\
Paciran & & \\
\hline
\end{tabular}

dari pemerintah apakah sudah memenuhi kebutuhan atau masih belum mencukupi kebutuhan pelaksanaan program.

Berjalannya suatu kegiatan tentu membutuhkan dana dalam pelaksanaannya. Berdasarkan hasil indept interview, ketersediaan dana yang ada untuk pelaksanaan surveilans lihat pada tabel 4 .

Menurut tabel 3 diatas, dapat dijelaskan bahwa untuk dana di Dinkes Kabupaten Lamongan tidak memiliki dana pelaksanaan dan pada tingkat puskesmas juga demikian sehingga untuk kecukupan tentu tidak cukup. Dari hasil indept interview didapatkan bahwa pneumonia belum ada dana pelaksanaan namun pernah mendapat bantuan berupa alat pemeriksaan yaitu soudtimer kepada setiap puskesms 1 buah, namun itu pada tahun 2012 dari APBD sehingga banyak yang sudah rusak.

\section{PEMBAHASAN}

Penelitian ini membahas tentang keadaan input sistem surveilans pneumonia di Dinkes Kabupaten Lamongan. Dari penelitian ini didapatkan beberapa kendala dan masalah. Penelitian ini hanya mengambil sistem input surveilans saja sehingga tidak mencantumkan proses dan output surveilans

Tabel 3. Sumber Daya Surveilans

\begin{tabular}{llcc}
\hline \multicolumn{1}{c}{ Petugas } & Pendidikan terakhir & $\begin{array}{c}\text { Riwayat mengikuti } \\
\text { pelatihan }\end{array}$ & Standart \\
\hline Dinkes & S1 Psikologi & Belum & Sudah \\
Puskesmas Dradah & SPK & Belum & Sudah \\
Peskesmas Paciran & S1 Keperawatan & Belum & Sudah \\
\hline
\end{tabular}


yang berjalan di Dinas Kesehatan Kabupaten Lamongan. Sistem input surveilans pneumonia sendiri meliputi

sumber data dan jenis data, sarana dan prasarana, sumber daya serta sumber dana. Di bawah ini merupakan pembahasan dari hasil input yang didapatkan melalui indepth tnterview kepada puskesmas dan rumah sakit selaku responden.

\section{Sumber Data}

Sumber data merupakan bagian terpenting dalam pengumpulan data. Data merupakan hasil temu yang membutuhkan pengolahan lagi bagi penerima data. Pada penelitian ini sumber data yang didapatkan bersumber dari puskesmas. Data yang didapatkan baik berupa dokumen, form, checklis atau yang lainnya. Pada penelitian ini jenis data berupa form pneumonia bulanan dari puskesmas yang dilaporkan dari Dinas Kesehatan Kabupaten ke Dinas Kesehatan PROVINSI.

Berdasarkan Keputusan Kementrian Kesehatan RI nomor 1116/MENKES/SK/ VIII/2003 tentang pedoman penyelenggaraan sistem surveilans epidemiologi kesehatan, terdapat penjelasan bahwa pada sistem pelaporan sumber data yang menyediakan tidak hanya bersumber dari puskesmas melainkan dari rumah sakit dan unit statistik lainnya. Tampak jelas bahwa dalam pengumpulan data surveilans pneumonia masih jauh dari kurang sebab sumber data yang bisa dikumpulkan dari rumah sakit dan klinik termasuk dalam data yang sangat penting dan memengaruhi perhitungan baik jumlah kesakitan maupun CFR.

Data yang diambil hanya berdasarkan pengumpulan data pneumonia dari puskesmas. Puskesmas selaku sumber data yang dikumpulkan dari rawat jalan yang bersumber dari laporan bidan desa yang dibawahi oleh puskesmas secara periodik, baik mingguan atau bulanan. Dalam hal ini dibutuhkan jaringan kerja sama yang lebih luas sehingga dapat menjangkau dari pihak rumah sakit dan klinik. Sehingga data yang dikumpulkan lebih maksimal untuk mengetahui keadaan perkembangan dan penyebaran penyakit pneumonia tersebut.

Sarana dan Prasarana

Sarana dan prasarana kegiatan surveilans pneumonia merupakan salah satu hal yang diperlukan untuk mendukung sebuah program penanggulangan penyakit pneumonia. Berdasarkan hasil indepth interview, sarana Dinas Kesehatan kabupaten Lamongan yaitu pemegang program pneumonia menggunakan laptop milik sendiri, penggunaan sofwere yang sudah berjalan dan printer, memiliki alat soundtimer dan buku panduan pneumonia. Pada sarana yang lain seperti formulir pencatatan laporan telah dimiliki. Sesuai dengan pedoman penatalaksanaan, Dinas Kesehatan harus memiliki soundtimer, sarana pencatatan dan pelaporan, dan buku panduan sudah memenuhi standart yang ditetapkan melalui kebijakan yang harus memiliki ketentuan yang sudah disebutkan (Kemenkes RI, 2011).

Pada tingkat puskesmas terdapat 1 alat yang dibutuhkan dalam pemeriksaan namun sudah terlalu lama. Sangat dibutuhkan bantuan alat baru serta tenaga yang terlatih dan trampil agar penggunaan alat lebih maksimal. Terkait dengan jumlah alat yaitu soundtimer puskesmas seharusnya memiliki 3 buah, namun pada kenyataannya hanya memiliki 1 buah. Berdasarkan pedoman pemakaian soundtimer yang sudah digunakan selama 2 tahun atau jika dilihat dari frekuensi penggunaannya 10.000 kali pemakaian, ada pula yang mengatakan bahwa 3 tahun maka soundtimer akan mengalami kerusakan. Ruangan untuk pemeriksaan sudah tersedia, namun tidak memiliki buku panduan pneumonia. (Kemenkes RI, 2011).

Pada realita yang ada, puskesmas jarang mengunakan soudtimer untuk melakukan pemeriksaan, hal tersebut dikarenakan pasien yang banyak sehingga untuk melakukan tata cara pemeriksaan sesuai dengan tata cara yang ada akan menghambat kerja petugas dan pasien akan mengantri lama. Hal tersebut juga akan mengakibatkan hasil dari pendiagnosaan penyakin bisa salah sehingga 
pasien yang kembali bisa jadi malah akan lebih parah sakitnya.

\section{Sumber Daya Surveilans}

Pelaksanaan surveilans pneumonia di Dinas Kesehatan Kabupaten Lamongan adalah 1 orang yang memiliki pendidikan terakhir S1 Psikologi, sehingga tidak sesuai dengan bidang yang dimiliki, namun dari D3 menempuh pendidikan D3 Akper sehingga mungkin sedikit mengerti akan penyakit. Sesuai dengan Kepmenkes Nomor 1116/MENKES/SK/VIII/2003 tentang Pedoman Penyelenggara Sistem Surveilans Epidemiologi Kesehatan tenaga surveilans adalah seorang epidemiologi terampil. Dari jenjang pendidikan yang dimiliki sedikit jauh dari ketentuan yang berlaku.

Petugas surveilans juga perlu untuk mengikuti kegiatan pelatihan yang bertujuan supaya petugas tersebut terampil dalam melaksanakan kegiatan surveilans. Petugas yang kurang terampil dan belum terlatih akan memengaruhi deteksi kasus, sesuai dengan faktor yang memengaruhi rendahnya cakupan penemuan pada Pedoman Pengendalian ISPA (Kemenkes RI, 2011). Petugas di Dinas Kesehatan Kabupaten Lamongan belum mengikuti pelatihan khusus Pneumonia, namun mengikuti pelatihan MTBS Pneumonia (Manajemen Terpadu Balita Sakit) dan MTBM (Manajemen Terpadu Balita Muda) yang sudah beberapa tahun yang lalu. Tidak menutup kemungkinan bagi pemegang program baru yang mungkin telah dipindahkan jabatannya di puskesmas tidak tau menau akan tatalaksanaan pasien dengan pneumonia.

Berdasarkan hasil penelitian, pendidikan yang dimiliki oleh kedua puskesmas tidak sesuai dengan bidang yang dipegang. Pada Puskesmas Dradah petugas surveilans memiliki pendidikan terakhir SPK dan pada Puskesmas Paciran memiliki pendidikan terakhir S1 Keperawatan. Sesuai dengan Kepmenkes Nomor 1116/ MENKES/SK/VIII/2003 tentang Sumber daya penyelenggara sistem surveilans epidemiologi kesehatan adalah tenaga ahli epidemiologi (S1, S2, S3). Jelas bahwa pada tingkat puskesmas jenjang yang sudah ditempuh oleh petugas di puskesmas Paciran dan puskesmas Dradah tersebut tidak sesuai dengan ketetapan.

Hasil penelitian juga menunjukkan bahwa para petugas surveilans mempunyai pekerjaan lain selain memegang program pneumonia dengan kata lain memegang beberapa program. Dari narasumber Dinkes Kabupaten Lamongan mengatakan bahwa selain memegang program surveilans pneumonia ada program lain yang dipegang sehingga tidak hanya fokus pada satu program melainkan beberapa program. Dalam pelaksanaan surveilans Pneumonia, petugas Dinas Kesehatan Kabupaten Lamongan melaksanakan semua sendiri dari pengumpulan data dari puskesmas hingga pelaporan ke Dinas Provinsi, sedangkan laporan dari Puskesmas ada yang masih menggunakan form lama harus memindah ke form yang baru. Hal tersebut menjadikan tidak maksimalnya pelaksanaan program. Sedangkan pada tingkat puskesmas yaitu pada puskesmas Dradah selain memegang program pneumonia juga memegang program lain begitu pula pada puskesmas Paciran juga mengatakan hal yang sama bahwa tidak hanya memegang 1 program melainkan beberapa program. Perlu adanya kebijakan dalam pembagian pemegang program yang mungkin bisa dengan penambahan staf ataupun yang lainnya sehingga setiap program kesehatan yang dijalankan berjalan sesuai dengan harapan yang diinginkan.

Pada sebuah penelitian oleh Choiriyah dan Dian (2015), yang diadakan di Puskesmas juga didapatkan tenaga yang bertugas dalam pelaksanaan hanya 1 para medis sehingga tidak sesuai dengan pedoman yang sudah ada, dari masalah ini juga muncul beberapa permasalahan, hal tersebut karena tuntutan kesehatan yang semakin tinggi sehingga peningkatan upaya kesehatan oleh tenaga kesehatan juga haus meningkat sedangkan petugas yang benar-benar mumpuni sangat 
terbatas. Tidak hanya itu, didapatkan pula petugas pemegang program juga belum mengikuti pelatihan atau seminar tentang pneumonia.

Dari keadaan yang ada ini, yang dapat dilakukan oleh Dinas kesehatan adalah meningkatkan keterampilan pemegang program surveilans pneumonia.

\section{Sumber Dana}

Pendanaan merupakan bagian pokok dalam keberlangsungan hidup suatu kegiatan. Jumlah dana yang ada akan memberikan dampak pada mutu pelayanan kesehatan yang diberikan oleh tenaga kesehatan. (Azwar, 2008).

Berdasarkan pada Keputusan Kementrian Kesehatan RI nomor 1116/ MENKES/SK/VIII/2003 tentang pedoman penyelenggaraan sistem surveilans epidemiologi kesehatan, dijelaskan tentang sumber dana yang bisa didapatkan untuk pelaksanaan program yang bersumber dari APBD Kabupaten/Kota, APBD Provinsi, APBN atau bantuan yang bisa bersumber dari mana saja. Namun pada kenyataan yang ada, untuk pelaksanaan program surveilans pneumonia di Dinas Kesehatan wilayah Kabupaten Lamongan belum ada bantuan sama sekali, pernah ada bantuan dari APBD yang berupa alat penghitung nafas atau disebut dengan soundtimer dan bantuan tersebut sulah lama diberikan.

Dari penelitian yang dilakukan oleh Choiriyah dan Dian (2015), menjelaskan keadaan yang ada di puskesmas bahwa tidak adanya dana juga, hal tersebut dikarenakan kegiatan penemuan penderita pneumonia belum ada kegiatan sama sekali. Selain dari penelitian tersebut, penelitian dari Pane (1998), menyatakan bahwa dana dan kebijakan tampak kurang mendukung terkait dengan kegiatan P2 ISPA ter khusus untuk kasus pneumonia yang terjadi di kota Bogor.

Ketidak adanya dana untuk program surveilans pneumonia tidak berarti bahwa program tidak berjalan namun ketidak maksimalnya program yang dapat dilihat dari sarana prasarana yang masih kurang. Hal tersebut menjadikan petugas yang melaksanakan surveilans terlebih dari sumber data akan merasa kurang bersemangat dalam menjalankan kegiatan surveilans pneumonia. Untuk sampai pada saat ini, apabila dari program pneumonia membutuhkan dana untuk pelaksanaan program maka akan diikutsertakan dengan program lain yang memiliki alokasi pendanaan yang cukup sehingga program pneumonia tetap berjalan. Kondisi seperti itu tidak mungkin akan berjalan terus menerus, tetap dibutuhkannya pendanaan untun program pneumonia sendiri, maka perlunya pengajuan dana agar program pneumonia sendiri memiliki alokasi dana sendiri tanpa harus diikutkan ke program lain dalam pendanaannya.

\section{SIMPULAN}

Pada penelitian ini telah didapatkan gambaran mekanisme sistem input surveilans pneumonia di Dinas Kesehatan Kabupaten Lamongan. Dari hasil penelitian yang didapatkan sistem input di Dinas Kesehatan Kabupaten Lamongan masih belum baik, terbukti hanya dari sistem input yang banyak kekurangannya. Hal tersebut bisa dilihat pada sistem input yang dilaksanakan Dinas Kesehatan Kabupaten Lamongan didapatkan masih kurangnya sumber data yang hanya bersumber dari 33 puskesmas, sedangkan dari rumah sakit dan klinik atau pelayanan kesehatan lainnya tidak melakukan pelaporan secara berkala, kemudian sarana prasarana yang tidak memadai, terbukti dari tidak adanya buku panduan pneumonia di tingkat puskesmas dan alat yang sudah terlalu lama. Dari sisi sumber daya yang dapat dilihat dari jenjang pendidikan yang dimiliki oleh petugas surveilans pneumonia di Dinas Kesehatan Kabupaten Lamongan maupun di tingkat Puskesmas belum sesuai dengan ketentuan yang sudah ditetapkan oleh pemerintah yaitu tenaga surveilans yang kompeten. Dan selanjutnya adalah sumber dana pelaksanaan program surveilans 
pneumonia yang tidak ada, sedangkan pendanaan merupakan faktor penting dalam pelaksanaan program dan sementara ini apabila dibutuhkan dana maka akan diikutkan dengan program lain. Perlu adanya evaluasi lebih mendalam untuk melengkapi kegiatan program pneumonia agar mencapai tujuan yang diinginkan, seperti dengan peningkatan hubungan dengan pelayanan kesehatan yang belum terjangkau oleh Dinas Kesehatan, penambahan sumber daya untuk pelaksanaan program sehingga tidak adanya penumpukan program yang dikelola oleh 1 petugas saja dan mengajukan dana supaya ada pendanaan untuk keberhasilan program.

\section{DAFTAR PUSTAKA}

Azwar, A. 2008. Pengantar Administrasi Kesehatan. Binarupa Aksara, Jakarta.

Badan Pusat Statistik (BPS), Badan Koordinasi Keluarga Berencana Nasional (BKKBN), Departemen Kesehatan, dan Macro Internasional. 2013. Survei Demografi dan Kesehatan Indonesia 2012.

Choiriyah, S., Dina N.A.N. 2015. Evaluasi Input Sistem Surveilans Penemuan Penderita Pneumonia Balita Di Puskesmas. Unnes Journal of Public Health. Volume 4, Oktober 2015: Halaman 139-142.

Ditjen P2PL. 2003. Surveilans Epidemiologi Penyakit (PEP) Edisi 1. Depkes RI, Jakarta.

Efendi F.M. 2009. Keperawatan Kesehatan Komunitas. Salemba Medika.

Fajriyah, Habibatin Nurul. 2016. Analisis Sistem Surveilans Pneumonia di Dinas Kesehatan Kabupaten Lamongan tahun 2014. Skripsi. Surabaya: Universitas Airlangga.

International Virtual Aviation Centre (IVAC). 2011. Pneumonia Progress Report 2011. IVAC. Baltimore.

Kementrian Kesehatan RI. 2014. Profil Kesehatan Indonesia 2013. Jakarta: Kementrian Kesehatan RI.
Keputusan Menteri Kesehatan RI. 2014. Peraturan Menteri Kesehatan Republik Indonesia nomor 45 tahun 2014 tentang Penyelenggaraan Surveilans Kesehatan. Jakarta: Departemen Kesehatan.

Kementerian Kesehatan RI. 2010. Modul Tatalaksana Standart Pneumonia. Jakarta. Katalog terbitan Kemenkes RI. Direktorat Jendral Pengendalian Penyakit dan Penyehatan Lingkungan.

Kementrian Kesehatan RI. 2011. Pedoman Pengendalian Infeksi Saluran Pernafasan Akut. Jakarta: Katalog terbitan Kemenkes RI. Direktorat Jenderal Pengendalian Penyakit dan Penyehatan Lingkungan.

Keputusan Menteri Kesehatan Republik Indonesia. 2003. Peraturan Menteri Kesehatan Republik Indonesia Nomor: 1116/MENKES/SK/VIII/2003 tentang Pedoman Penyelenggaraan Sistem Surveilans Epidemiologi Kesehatan. Jakarta: Departemen Kesehatan.

Keputusan Menteri Kesehatan Republik Indonesia. 2003. Peraturan Menteri Kesehatan Republik Indonesia Nomor: 1457/MENKES/SK/X/2003 tentang Standar Pelayanan Minimal Bidang Kesehatan di Kabupaten/Kota. Jakarta: Departemen Kesehatan.

Keputusan Menteri Kesehatan Republik Indonesia. 2003. Peraturan Menteri Kesehatan Republik Indonesia Nomor: $1479 / M E N K E S / S K / X / 2003$ tentang Pedoman Penyelenggaraan Sistem Surveilans Eidemiologi Penyakit Menular dan Penyakit tidak Menular Terpadu. Jakarta: Departemen Kesehatan.

Moenir, H.A.S. 2001. Manajemen Pelayanan Umumdi Indonesia, Bumi Aksara, Jakarta.

Pane, M. 1998. Evaluasi Penemuan dan Pengobatan Penderita Infeksi Saluran Pernafasan Akut (ISPA) Pneumonia Pada Baita Melalui Surveilans Epidemiologi ISPA di Kotamadya Bogor Tahun 19941997. Skripsi. Universitas Diponegoro, Semarang. 